\title{
Design of Mechanical Arm for Laser Weeding Robot
}

\author{
Ge Zhenyang $^{\mathrm{a}}$, Wu Wangwang ${ }^{\mathrm{b}}$, Yu Yingjie ${ }^{\mathrm{c}}$, Zhang Ruiqing ${ }^{\mathrm{d}}$ \\ Department of Agricultural Engineering \\ Kunming University of Science and Technology \\ Kunming, China \\ e-mail: 'ge.27@kmust.edu.cn, ${ }^{b} 287229665 @ q q . c o m,{ }^{\mathrm{c}} 646677093 @ q q . c o m,{ }^{\mathrm{d}}$ zrq0830@126.com
}

\begin{abstract}
A design of mechanical arm for laser weeding robot is described. The long term objective of the project is the replacement of chemical weeding by laser weeding. The distinguishing feature of this design is the use of a mechanical arm, which is equipped with a laser generator and a control center consisted of a single chip microcomputer and two driver hybrid ICs. The mechanical arm comprises two stepping motors vertically linked together. The robot moves ahead one step, the working area of laser generator is divided into $10 \times 10$ grids. Through the inverse operation of mechanical arm, the motor displacement angle of each grid is calculated. Mechanical arm turns to designated position if single chip gets weeds position information. The result of the design is a key executive mechanism of laser weeding. The operation error of mechanical arm is analyzed. The arm can point the laser beam towards the target weeds with small error. After the order of the execution areas is optimized, the length of arm moving path is shorter. Analysis of the running track shows that the sequence of execution area is feasible and reasonable.
\end{abstract}

Keywords-mechanical arm; single chip microcomputer; laser; weeding;

\section{INTRODUCTION}

Improving agricultural resources utilization, agricultural output rate and agricultural economic benefit is the trend of the development of modern agriculture. In traditional farmland management, spraying chemical herbicides is the main way to control weeds. But this method has many disadvantages.

In recent years, herbicides in relation to food safety, farm workers health, biodiversity, and the environment has being concerned. In general, researchers have renewed interest in alternative weed control measures. The main alternatives are physical weed control methods such as mechanical hoeing, harrowing, and brushing, which uproot or cover the weeds by soil, thereby stopping or delaying the growth and thus increasing the competitive advantage of the crop [1-4]. These methods are normally limited to inter-row weed control and due to their disturbance of the upper soil layer, they may initiate new weed seed germination. This undesirable effect of the weed control action can be eliminated using thermal soil treatment methods $[5,6]$.

As a way to concentrate and control the use of energy while avoiding mechanical action, lasers have been considered as a cutting device for physical weed control [78]. The test results showed that laser can significantly inhibit the growth of weeds instead of pesticide effect on weeds. It sometimes can make some weeds varieties died and also can achieve the effect of weeding. Extensive research of the effect of laser treatment as a weed control method and laser weeding robot is developed in recent years [9-12].

The research of laser weeding robot is of importance and significance. Laser weeding robot can improve labor productivity, solve the shortage of the labor force, improve the environment of agricultural production, prevent harm of human body caused by pesticide and improve work quality. Compared with the traditional weeding machines, it can better combined with agronomy. Laser weeding robot can reduce energy waste, improve resource utilization, and help farmers to change their traditional working way and labor condition.

This paper mainly introduces the design of a mechanical arm for laser weeding robot and the mechanical arm motion controls. The arm is the key part of the laser weeding robot. Through inverse kinematic computation, displacement angles of two steppers can be obtained. In doing so, it is necessary to optimize the executive trace.

\section{MATERIALS AND METHODS}

\section{A. Mechanical Arm System}

This mechanical arm system is consisted of a MCU (single chip microcomputer STC89C52) as the control center, a mechanical arm and two drive IC (integrated circuit). The mechanical arm has two stepping motors vertically linked together. Two STK672-050 driver hybrid ICs are used to control the rotation of stepping motor. In the forepart of mechanical arm, a laser generator is equipped. By using image processing to get the exact position of the weeds, relative information will be sent into the MCU. Then stepping motors run a certain angle and move the laser transmitter pointing toward weeds. Fig. 1 shows the structure of mechanical arm.

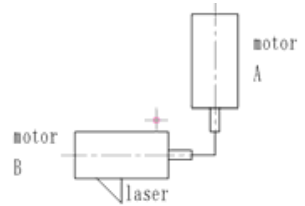

Figure 1. Structure of mechanical arm 


\section{B. Algorithm and Optimizing}

The height of laser transmitter relative to ground is $300 \mathrm{~mm}$. The $300 \mathrm{~mm} \times 300 \mathrm{~mm}$ area of image acquisition is divided into $100(10 \times 10)$ grids. Starting position of laser sets in the lower-left corner. The initial displacement angles of both stepping motors are 0 . And each grid center coordinate relative to the initial position can be determined. Table 1 lists 20 grid parameters from 100 grids.

Through the inverse operation of mechanical arm, the motor displacement angle can be calculated, equation(1) shows the mathematical model. In Fig.2, $\alpha$ is the displacement angle of motor $A$ and $\beta$ is the displacement angle of motor $\mathrm{B}, \mathrm{h}$ is the height of laser transmitter relative to ground.

$$
(X, Y)=h \times \tan \beta \times(\cos \alpha, \sin \alpha)
$$

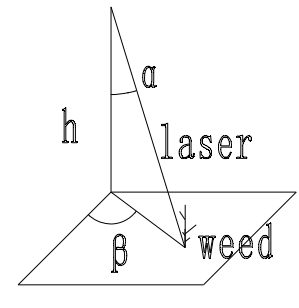

Figure 2. Weeding

According to position of each grid, two step motors displacement angles corresponding each regional center can be achieved. Due to limits of the step angle of stepper, execution of mechanical arm is discontinuous. Step angle of stepper is $1.8^{\circ}$ and the drive control card can achieve 16 segments. So the stepper minimum step angle is $1.8^{\circ} / 16$. Optimization results are shown in Table 1.

\section{Error Analysis and Path Simulation}

The executive angle of stepper and optimal execution angle got by inverse operation have differences. So the error analysis is necessary. From table 1, the maximum error is

$$
\Delta \max =\sqrt{\Delta \max X^{2}+\Delta \max Y^{2}} \approx 0.64 \mathrm{~mm}
$$

Where, $\Delta \max X=0.4 \mathrm{~mm}, \Delta \max Y=0.5 \mathrm{~mm}$.

Use MATLAB to simulate actual operation trace. The points are selected in random. Corresponding parameters of 5 grids are showed in Table 2 .

TABLE II. RANDOM GRID PARAMETERS

\begin{tabular}{|l|c|c|c|c|c|}
\hline $\begin{array}{l}\text { Random } \\
\text { number }\end{array}$ & $\mathbf{1}$ & $\mathbf{2}$ & $\mathbf{3}$ & $\mathbf{4}$ & $\mathbf{5}$ \\
\hline Coordinates & $\begin{array}{c}244.4, \\
29.2\end{array}$ & $\begin{array}{c}271.7, \\
83.5\end{array}$ & $\begin{array}{c}38.0, \\
164.0\end{array}$ & $\begin{array}{c}274.0, \\
287.2\end{array}$ & $\begin{array}{c}189.7, \\
289.4\end{array}$ \\
\hline $\begin{array}{l}\text { Corresponding } \\
\text { grid }\end{array}$ & 81 & 93 & 16 & 100 & 80 \\
\hline $\begin{array}{l}\text { coordinates of } \\
\text { grid }\end{array}$ & $\begin{array}{c}254.9, \\
15.1\end{array}$ & $\begin{array}{c}285.2, \\
74.8\end{array}$ & $\begin{array}{c}45.2, \\
75.2\end{array}$ & $\begin{array}{c}284.6, \\
284.6\end{array}$ & $\begin{array}{c}224.8, \\
284.6\end{array}$ \\
\hline
\end{tabular}

Implement result is shown in Fig.4. The trace is chaos. It is necessary to optimize order of the execution areas. Two optimization constraint functions can be used.
Three kinds of trace model were used: a. no optimizing, b. distance between starting point and execution point, c. minimum path between adjacent point optimizing. In order to receive good effect, the movement path of each model is compared.

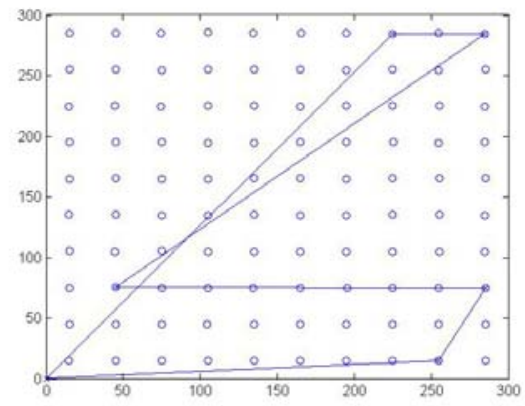

Figure 3. No optimal trajectory

- The distance between starting point and execution point is chosen as optimization function. Point close to the starting point will be firstly processed. Constraint function such as model (3) shows,

$$
\mathrm{Q}(\mathrm{m})<\mathrm{Q}(\mathrm{m}-1)<\ldots<\mathrm{Q}(1)
$$

Where, $\mathrm{Q}(\mathrm{m})$ is the distance between No.m grid and starting position. Firstly, No.m grid will be processed. So, the processing order of randomly selected grids are No.16, No.81, No.93, No.80, No.100. Implement results is shown in Fig.4.

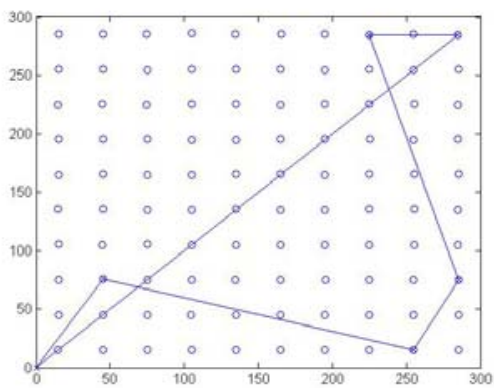

Figure 4. Distance between starting point and execution point optimal trajectory

- The distance between initial position and the last grid is chosen as optimization function. Constraint function expressed by formula (4) can ensure minimum distance for the trace.

$$
\min \sum_{i=0}^{n} f(p)
$$

where, $\sum_{i=0}^{n} f(p)=\sum_{i=0}^{n-1} \sqrt{\left(x_{i}-x_{i+1}\right)^{2}+\left(y_{i}-y_{i+1}\right)^{2}}$.

After optimization, the executive order is No.16, No.81,No.93, No.100 and then No.80. Implement result is shown in Fig.5. 


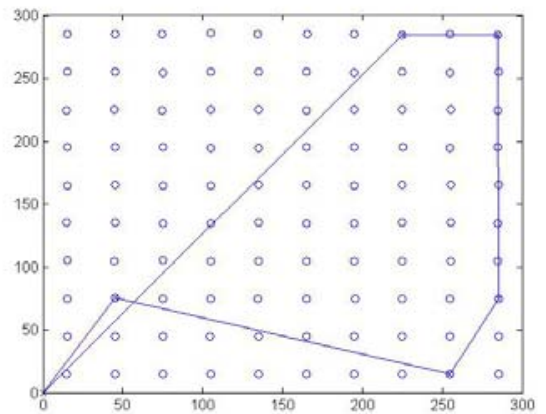

Figure 5. Minimum path optimization

\section{MCU Programming}

In the execution of the program, relative weeds position informations will be sent to run function for making the laser transmitter point toward this point. Laser function controls the switch of laser. When actuator reaches execution grid, the switch of laser will be opened with a certain time. Laser processing time is controlled by the delay function. Parts of the programs are shown below.

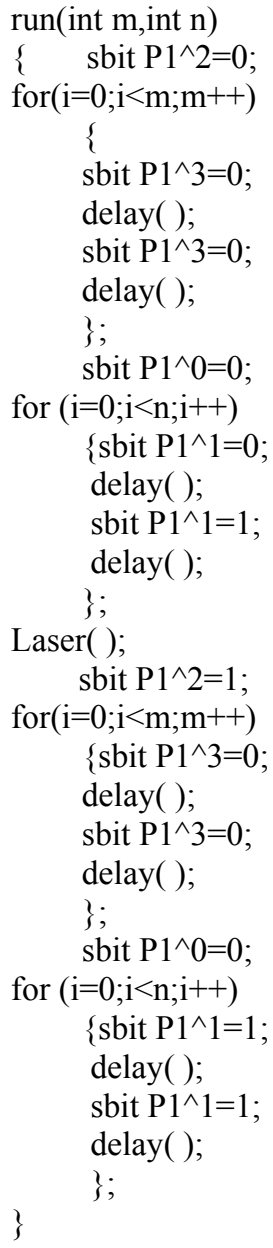

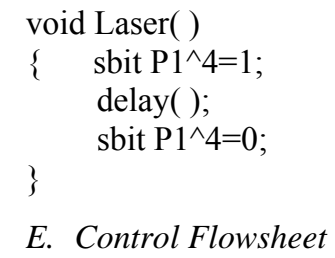

\section{E. Control Flowsheet}

The control flowsheet of actuator is shown in Fig.6. The weeds position are determined by image processing, and the information will be sent to the MCU. Then stepping motors run a certain angle make the laser transmitter point toward weeds and lase. The weeding procedure is performed. If there are $\mathrm{n}$ grids, by using model 3 , the order of the execution grids will be optimized. While weeds grid $n$ is processed, the MCU will judge whether all weeds areas are completed. If not, the next weed grid will be processed. If it is completed, the progress will be ended and the laser weeding robot will go to get next image information.

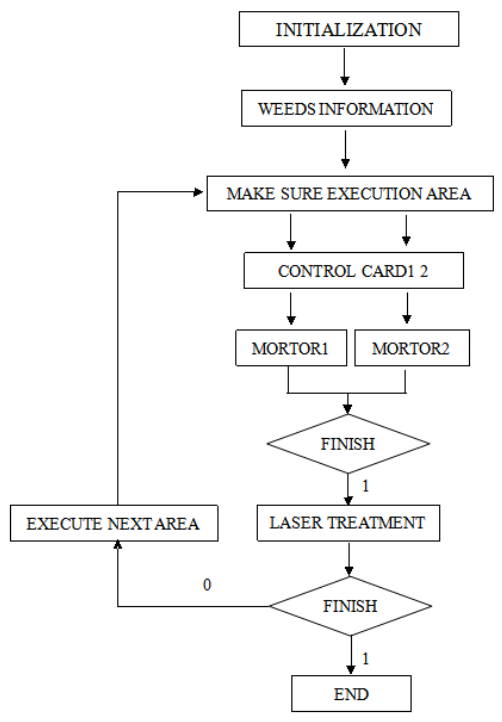

Figure 6. Control flowsheet

\section{DISCUSSION}

Through inverse operation of control, each execution area corresponding displacement angle is obtained. According to the features of stepper motors and drive card, displacement angles are optimized. The MCU control procedure is designed. The result of the design is a key mechanism of laser weeding. The operation error of mechanical arm is analyzed. The arm can point the laser beam towards the target with small error. After optimizing the order of execution grids, the length of arm moving path is shorter.

The results indicate that it is possible to apply the mechanical arm to laser weeding robot and to obtain a better performance by using path optimization. The results also indicated that the efficacy of path optimization can be improved by a proper selection of algorithm. 
In order to improve the performance and to travel less distance in the process of weeding, further research and development are needed.

\section{REFERENCES}

[1] Pullen D W M; Cowell P A (1997). An evaluation of the performance of mechanical weeding mechanisms for use in high speed inter-row weeding of arable crops. Journal of Agricultural Engineering Research, 67(1), 27-34

[2] Tillett N; Hague T (1999). Computer-vision-based hoe guidance for cereals - an initial trial. Journal of Agricultural Engineering Research, 74(3), 225-236

[3] Bond W; Grundy A C (2001). Non-chemical weed management in organic farming systems. Weed Research, 41(5), 383-406

[4] Solvejg K. Mathiassen; Thomas Bak; Svend Christensen; Per Kudsk. The Effect of Laser Treatment as a Weed Control Method. Biosystems Engineering (2006) 95 (4), 497-505

[5] Shaw L N; Mitchell D J (1977). A continuous soil pasteurizer for organic nursery potting mixtures. ASAE Paper No.74-1502

[6] Melander B; Jogensen M H (2005). Soil steaming to reduce intrarow weed seedling emergence. Weed Research, 45(3), 202-211
[7] Heisel T; Schou J; Christensen S; Andreasen C (2001). Cutting weeds with a CO2 laser. Weed Research, 41(1), 19-29

[8] Christensen S; Heisel T; Schou J (2003). Severing or damaging apparatus for unwanted plants comprises an optical recognition system that differentiates between different types of plants with a light generating source to expose the plant to electromagnetic radiation. Patent Number(s): AU9948982-A; WO200003589-A1. International Patent Classification: A01M-021/00

[9] Jacobsen B H, Madsen N, Ørum J E. Organic farming at the farm level-scenarios for the future development[R].Copenhagen: Food and Resource Economic Institute, 2005.

[10] Terawaki M, Kataoka $\mathrm{T}$, Okamoto $\mathrm{H}$, et al. Development of automatic weeding thinner for sugar beet[A]. 2003 ASAE Annual International Meeting[C]. Las Vegas, USA, Hokkaido University, 60 $-66$

[11] Chen Yong, Zheng Jiaqiang, Guo Weibin. Kinematics analysis and motion control for a weeding robotic $\operatorname{arm}[\mathrm{J}]$. Transactions of The Chinese Society of Agricultural Machinery, 2007, 38(8): 105 - 108.

[12] Qiu Baijing, Qian Guohong, Zhou Ning, et al. Avoiding barriers control of mowing robot[J]. Journal of Jiangsu University (National Science Edition), 2005, 26(4): 285-288.

TABLE I. DIVISION AND CORRESPONDING MOTOR PARAMETER

\begin{tabular}{|c|c|c|c|c|}
\hline \multirow[t]{2}{*}{ Grid number } & \multicolumn{4}{|c|}{ Grid parameters } \\
\hline & $\begin{array}{c}\text { Coordinates of } \\
\text { regional center } \\
(x, y) /(\mathrm{mm})\end{array}$ & $\begin{array}{c}\text { Step motor } \\
\text { displacement angle } \\
(\alpha 1, \quad \beta 1) /\left(^{\circ}\right)\end{array}$ & $\begin{array}{c}\text { Optimized coordinates } \\
\text { of grid } \\
(x 1, y 1) /(\mathrm{mm})\end{array}$ & $\begin{array}{c}\text { Number of control } \\
\text { pulsing signal } \\
(n 1, n 2)\end{array}$ \\
\hline 1 & 15,15 & $45.0,4.0$ & $14.8,14.8$ & 400,36 \\
\hline 2 & 15,45 & $71.6,9.0$ & $15.0,45.1$ & 636,80 \\
\hline 3 & 15,75 & $78.7,14.3$ & $15.0,75.0$ & 700,127 \\
\hline 4 & 15,105 & $81.9,19.5$ & $15.0,105.2$ & 728,173 \\
\hline 5 & 15,135 & $83.7,24.4$ & $14.9,135.2$ & 744,217 \\
\hline 6 & 15,165 & $84.8,28.9$ & $15.0,164.9$ & 754,257 \\
\hline 7 & 15,195 & $85.6,33.1$ & $15.0,195.0$ & 761,294 \\
\hline 8 & 15,225 & $86.2,36.9$ & $14.9,224.8$ & 766,328 \\
\hline 9 & 15,255 & $86.6,40.4$ & $15.1,254.9$ & 770,359 \\
\hline 10 & 15,285 & $87.0,43.6$ & $15.0,285.3$ & 773,388 \\
\hline 11 & 45,15 & $18.4,9.0$ & $45.1,15.0$ & 164,80 \\
\hline 12 & 45,45 & $45.0,12.0$ & $45.1,45.1$ & 400,107 \\
\hline 13 & 45,75 & $59.0,16.3$ & $45.2,75.2$ & 524,145 \\
\hline 14 & 45,105 & $66.8,20.8$ & $44.9,104.7$ & 594,185 \\
\hline 15 & 45,135 & $71.6,25.4$ & $45.0,135.2$ & 636,226 \\
\hline 16 & 45,165 & $74.7,29.7$ & $45.2,165.1$ & 664,264 \\
\hline 17 & 45,195 & $77.0,33.7$ & $45.0,194.9$ & 684,300 \\
\hline 18 & 45,225 & $78.7,37.4$ & $44.9,224.9$ & 700,332 \\
\hline 19 & 45,255 & $80.0,40.8$ & $45.0,255.0$ & 711,363 \\
\hline 20 & 45,285 & $81.0,43.9$ & $45.2,285.1$ & 720,390 \\
\hline
\end{tabular}

